${ }_{5}^{4}$ Dent, C. E., Birth Defects, Original Article Series, 7 (6), 79 (1971).

5 Nicolaysen, R., Eeg-Larsen, N., and Malm, O. J., Physiol. Rev. 33, 424 (1953).

6 Callow, R. K., Kodicek, E., and Thompson, G. A., Proc. R. Soc., B164, 1 (1966).

7 Neville, P. F., and DeLuca, H. F., Biochemistry, 5, 2201 (1966).

${ }^{8}$ DeLuca, H. F., Rec. Prog. Horm. Res., 27, 479 (1971).

9 Tucker, G. III, Gagnon, R. E., and Haussler, M. R., Archs. Biochem. Biophys., 155, 47 (1973).

10 Haddad, J. G. Jr., and Chyu, K. J., J. clin. Endocrinol. Metab., 33, 992 (1971).

11 Dent, C. E., Round, J. M., Rowe, D. J. F., and Stamp, T. C. B., Lancet, i, 1282 (1973).

12 Haddad, J, G., Nature, 244, 515 (1973).

13 Zull, J. E., Czarnowska-Misztal, E., and DeLuca, H. F., Proc. natn. Acad. Sci. U.S.A., 55, 177 (1966)

14 Lawson, D. E. M., Wilson, P. W., and Kodicek, E., Biochem. J., 115, 269 (1969)

15 Kodicek, E., Lawson, D. E. M., and Wilson, P. W., Nature, 228, 763 (1970)

16 Fraser, D. R., and Kodicek, E., Nature, 228, 764 (1970).

17 Lawson, D. E. M., Fraser, D. R., Kodicek, E., Morris, H. R., and Williams, D. H., Nature, 230, 228 (1971).

18 Holick, M. F., Schnoes, H. K., and DeLuca, H. F., Proc. natn. Acad. Sci. U.S.A., 68, 803 (1971).

19 Norman, A. W., Myrtle, J. F., Midgett, R. J., Nowicki, H. G., Williams, V., and Popjak, G., Science, N.Y., 173, 51 (1971).

${ }^{20}$ Holick, M. F., Garabedian, M., and DeLuca, H. F., Science, N.Y., 176, 1146 (1972).

21 Raisz, L. G., Trummell, C. L., Holick, M. F., and DeLuca, H. F., Science, N.Y., 175, 768 (1972).

22 Haussler, M. R., Boyce, D. W. Littledike, E. T., and Rasmussen, H., Proc. natn. Acad. Sci., U.S.A., 68, 177 (1971).

23 Boyle, I. T., Miravet, L., Gray, R. W., Holick, M. F., and DeLuca, H. F., Endocrinology, 90, 605 (1972).

${ }^{24}$ Brumbaugh, P. F., and Haussler, M. R., Biochem. biophys. Res. Commun., 51, 74 (1973).
25 Haussler, M. R., and Norman, A. W., Proc. natn. Acad. Sci., U.S.A., 62, 155 (1969).

${ }^{26}$ Corradino, R. A., and Wasserman, R. H., Science, N.Y., 179 , 402 (1971).

27 MacGregor, R. R., Hamilton, J. W., and Cohn, D. B., Clin. Orthop. Rel. Res., 78, 83 (1971).

28 Corradino, R. A., Nature, 243, 41 (1973).

29 Tsai, H. C., Midgett, R. J., and Norman, A. W., Archs Biochem. Biophys., 157, 339 (1973).

30 Boyle, I. T., Gray, R. W., and DeLuca, H. F., Proc, natn. Acad. Sci., U.S.A., 68, 2131 (1971).

31 Omdahl, J. L., Gray, R. W., Boyle, I. T., Knutson, J., and DeLuca, H. F., Nature, 237, 62 (1972).

32 Holick, M. F., Schnoes, H. K., DeLuca, H. F., Gray, R. W., Boyle, I. T., and Suda, T., Biochemistry, 11, 4251 (1972).

${ }^{33}$ Garabedian, M., Holick, M. F., DeLuca, H. F., and Boyle, I. T., Proc. natn. Acad. Sci., U.S. A., 69, 1673 (1972).

${ }^{34}$ Fraser, D. R., and Kodicek, E., Nature, 241, 163 (1973).

35 Rasmussen, H., Wong, M., Bikle, D., and Goodman, D. P. B., J. clin. invest., 51, 2502 (1972).

36 Tanaka, Y, and DeLuca, H. F., Archs Biochem. Biophys., 154, 566 (1973).

37 Tanaka, Y., Frank, H., and DeLuca, H. F., Science, N.Y., 181, 564 (1973).

38 Larkins, R. G., MacAuley, S. J., Colston, K., Evans, I., Galante, L., and MacIntyre, I., Lancet, ii, 289 (1973).

${ }^{39}$ Galante, L. S., Colston, K. W., Ėvans, I. M., Byfield, P. G. H., Matthews, E., and MacIntyre, I., Nature, 244, 438 (1973).

${ }^{40}$ Lotz, M., Ney, R., and Bartter, F. C., Trans. Ass. Am. Physns, 77, 281 (1964).

${ }^{41}$ Lotz., M., Zisman, E., and Bartter, F. C., New Engl. J. Med., 278, 409 (1968).

42 Boyle, I. T., Omdahl, J. L., Gray, R. W., and DeLuca, H. F., J. biol. Chem., 248, 4174 (1973).

43 Haussler, M. R., Zerewekh, J. E., Hesse, R. H., Rizzardo, E., and Pechet, M. M., Proc. natn. Acad. Sci. U.S.A., 70, 2248 (1973).

\title{
New Mode of Aerodynamics
}

IT is now well established that most flying insects depend, for their lift and thrust, on conventional aerofoil action which sets up a bound vortex around the moving wing to create a steady-state flow of air and thus provide the necessary aerodynamic cross-force. Weis-Fogh has shown that the same mechanism is used by most insects during hovering flight. But there have been claims that certain insects, notably lamellicorn beetles, must make use of non-steady principles to a large extent. Indeed, because wing movements are oscillatory, and the propeller action is achieved by the twisting of the wing at the end of each upstroke and downstroke, there are necessarily non-steady periods in the flight of all insects, particularly at these reversal points where active pronation and supination of the wings take place. In the August number of the Journal of Experimental Biology (59, 169; 1973) Weis-Fogh describes a reinvestigation of the capacity of insects for hovering flight which has demonstrated that in certain insects these twisting movements themselves generate aerodynamic forces of a completely novel character which provide the main source of lift.

In studying the flight of the minute chalcid wasp Encarsia formosa, which has a Reynolds number of only 10-20 (in place of 100-10,000 in most flying animals), it became evident from calculation that flight could not be explained on the basis of conventional aerodynamics. High speed cinematography revealed that, whatever the orientation of flight, the wings are first raised vertically above the thorax and clapped together in apposition; they are then actively flung apart, like the opening of a book, being pronated with the posterior margins remaining in apposition. Weis-Fogh calculates that this movement, which he terms the 'fling', will set up a temporary vortex around the wing and provide enough lift to sustain flight. This airflow will die away as the wings separate. But when they reach the lower limit of their excursion the wings are rapidly twisted in the reverse sense and supinated before the upstroke. This twisting movement, called the 'flip', will also set up a vortex around the wing and Weis-Fogh suggests (although exact calculation has not yet been possible in this case) that useful lift is again generated.

This new type of non-steady aerodynamics opens a wide field for future study. Non-steady periods, particularly 'flip' effects, are present in all flapping animals and they will be superimposed on the steady-state pattern. Weis-Fogh shows that the 'fling' operates in butterflies which likewise clap their wings above the thorax; there is preliminary evidence that the 'flip' is used by large hovering dragonflies and by the true hoverflies (Syrphinae). It was earlier shown that the hovering of Drosophila could be just accounted for in terms of conventional aerodynamics, but it is likely that the new mechanism makes a large contribution to the flight of these very small insects. The flight of insects is largely dependent on the storage of energy, generated in the movement of the wings, within elastic structures of the thorax, to be utilized for the reciprocal movement. There is suggestive evidence that the wing twistings occur so rapidly that the speed of propagation of the elastic torsional wave from base to tip of the wings plays an important part in hovering insects. Non-steady aerodynamics may well be utilized by bats, and the familiar 'clap' of pigeons taking off in a confined space strongly suggests that the 'fling' mechanism has been discovered also by birds.

From our Insect Physiology Correspondent 